were in the range of normal, while those of Cases 2, 3, and 6 were in the range of heterozygotes (Padeh and Navon, 1971). The prenatal diagnosis of Tay-Sachs disease in Case 7 was likewise confirmed by the absence of hexosaminidase $\mathrm{A}$ activity in the fetal tissues, both by the heat inactivation method and by starch-gel electrophoresis and also by the almost threefold increase in amount of the $\mathrm{GM}_{2}$ ganglioside in the brain as compared with the normal fetus of the same age.

In conclusion, the procedure described above seems at present to be a most reliable method for the prenatal diagnosis of Tay-Sachs disease.

We are grateful to Professor D. M. Serr and his department for performing the amniocenteses; to Dr. S. Mashiah and Dr. S. Pollak for their care of the patients; to Professor S. Gatt and Mr. A. Hertzel for helping us in the analysis of the gangliosides; to Mrs. Z. Mark and Mrs. S. Sahar for their technical help; and to Dr. A. Adam and Dr. R. M. Goodman for their critical comments.

This work was supported in part by a grant from the Chief Scientist's Office, Ministry of Health, Israel.

ADDENDUM: After this manuscript had been submitted for publication an article by O'Brien et al. (1971) describing similar results was published. We have since tested amniotic cells from three additional obligatory heterozygous women for hexosaminidase A. In two cases no activity of hexosaminidase A was found in cultured amniotic cells, indicating a Tay-Sachs disease fetus. This diagnosis was again confirmed on examination of the fetal tissues after therapeutic abortion. In the third case an activity of $34 \%$ of hexosaminidase A was found in the cultured amniotic cells. This activity is distinctly lower than that observed in the normal range, and thus the fetus was considered to be heterozygous.

\section{References}

Gatt, S., and Berman, E. R. (1963). Fournal of Neurochemistry, 10, 43

Friedland, J., Schneck, L., Saifer, A., and Volk, B. W. (1970). Clinica Chimi J., Sch,

Nadler, H. L. (1968). Biochemical Genetics, 2, 119.

Navon, R., and Padeh, B. (1971). Fournal of Pediatrics, (In Press)

O'Brien, J. S., Okada, S., Chen, A., and Fillerup, D. L. (1970). New England Fournal of Medicine, 283, 15.

O'Brien, J. S., et al. (1971). Science, 172, 61

Okada, S., and O'Brien, J. S. (1969). Science, 165, 698

Padeh, B., and Navon, R. (1971). Israel fournal of Medical Sciences, 7, 259.

Rattazzi, M. C., and Davidson, R. G. (1970). American fournal of Human Genetics, 22, 41 a (abstract).

Robinson, D., and Stirling, J. H. (1969). Biochemical fournal, 107, 321.

Schneck, L., et al. (1970). Lancet, 1, 582.

Svennerholm, L. (1957). Biochimica et Biophysica Acta , 24, 604.

\title{
Comparison of Corticotrophin and Prednisolone in Treatment of Idiopathic Facial Paralysis (Bell's Palsy)
}

\author{
D. TAVERNER, S. B. COHEN, B. C. HUTCHINSON
}

British Medical fournal, 1971, 4, 20-22

\section{Summary}

In a controlled trial of the effects of intramuscular corticotrophin and oral prednisolone in the treatment of acute Bell's palsy 186 successive patients with idiopathic facial palsy were grouped for age and duration of palsy. They were then allocated at random to either corticotrophin or prednisolone therapy in pairs. The results were:

(1) 94 received corticotrophin and 32 developed some degree of denervation and 92 received prednisolone and 13 developed some degree of denervation $(P<0.005)$; (2) six of the corticotrophin group became severely denervated (less than $50 \%$ recovery) compared with none of the prednisolone group $(P<0.02)$; $(3)$ the best results were obtained in the younger patients (less than 45 years old) treated on the first or second day of palsy; and (4) side effects were minimal.

It is concluded that oral prednisolone is the treatment of choice for idiopathic facial (Bell's) palsy. \footnotetext{
Department of Electromyography, General Infirmary, Leeds

D. TAVERNER, M.D., F.R.C.P., Consultant Physician

S. B. COHEN, M.B., M.R.C.P., Senior Medical Registrar (Present address : Clatterbridge Hospital, Wirral, Cheshire)

B. C. HUTCHINSON, M.B., CH.B., Medical Registrar (Present address: St. James's Hospital, Leeds)
}

\section{Introduction}

Evidence has previously been presented that daily injections of corticotrophin significantly reduce the overall incidence both of denervation and of severe degrees of denervation carrying permanent disability in Bell's palsy (Taverner et al., 1966). It has sometimes been claimed that corticotrophin is more effective than oral steroid therapy in the treatment of inflammatory neurological disorders (Jönsson et al., 1951; Ross et al., 1958; Miller et al., 1961) but firm supporting evidence is lacking. After a suggestion from Professor $\mathrm{H}$. Miller (personal communication, 1966) it was decided to compare these two agents in the treatment of Bell's palsy. The results of this trial are now reported.

\section{Design of Trial}

Only patients who were having their first attack of facial palsy and were aged 21 to 70 years inclusive were admitted. Those with clinical or laboratory evidence of herpes zoster were excluded. Also excluded were those with a history of peptic ulceration; with evidence of active infection, especially of the middle ear; with evidence of more widespread neurological disease; with known hypertension; with diabetes mellitus; or in the first six months of pregnancy. Patients with an incomplete facial palsy, plus an anodal galvanic threshold of less than $10 \mu \AA$ or less than $5 \mu \AA$ difference between each side of the tongue (Peiris and Miles, 1965), and with no hyperacusis or subjective taste disturbance were also excluded.

The time of onset of the palsy was taken as the day that weakness of the face was first noticed. This was counted as day 1 and patients were admitted up to day 4 .

Patients were entered chronologically into four groups; two 
for age (21 to 45 and 46 to 70 years) and two for duration of the palsy (one to two days; and three to four days). Treatment with corticotrophin* or prednisolone was allocated on a random basis in each group, in pairs for sequential analysis. Doses used were:

Prednisolone
$20 \mathrm{mg}$ q.d.s. for five days
$20 \mathrm{mg}$ t.d.s. for one day
$20 \mathrm{mg}$ b.d. for one day
$20 \mathrm{mg}$ daily for one day
$10 \mathrm{mg}$ daily for one day

Corticotrophin

60 units/day for five days 40 units/day for two days 20 units/day for two days

Patients were seen weekly for one month, then monthly for three months, and then three-monthly up to nine months unless completely recovered. The degree of movement of the forehead and corner of the mouth and of eyelid closure was assessed as a percentage of the sound side, and the presence of any associated movements on eye closure or retraction of the mouth was carefully noted. Any unilateral associated movement at all, however slight, was taken as evidence of denervation and therefore indicated failure of that particular treatment. All the patients were photographed at their last attendance. Four half-plate black-and-white prints of full face-at rest, eyes tightly closed, showing the teeth, and raising the eyebrowswere prepared. These photographs were used by an independent observer to check the results. When the second assessment differed from the first by more than $5 \%$ the patient was recalled for review by the second observer. There were only two differences of opinion in the complete recovery group-on review one case was confirmed as complete recovery and one was judged as having denervated slightly. Nineteen of the denervated group were reviewed and in each case the verdict of the independent observer was adopted. None of these was classified as complete recovery. One patient died and one was in America-in these the original category was adopted.

\section{Results}

One hundred and eighty-six patients completed the trial and 293 were rejected for the reasons given in Table I. The 22 patients rejected because of incomplete facial palsy plus normal

TABLE I-Details of 293 Patients Not Admitted to Trial

Wrong age group

Attended too late

Previous palsy $\ldots$ or anodal galvanic threshold difference

Due to herpes zoster

Part treated already in wrong dosage.

Contraindications and alternative diagnoses

*4 hypertension, 4 otitis media, 1 carcinomatous neuropathy, 1 head injury with discharge, and 1 brucellosis.

anodal galvanic threshold and/or no subjective taste loss were followed up separately-19 recovered completely, 1 died, and 2 recovered $95 \%$ of normal function and regarded themselves as cured.

Four patients were removed after acceptance because of incomplete therapy or failure of follow-up and were replaced in that pair by the next suitable new patient. One of the trial patients died before the final assessment could be made and too late for a substitute to enter the pair. As a result 91 pairs were finally assessed-58 were tied pairs ( 55 with no denervation and 3 both denervated), 26 showed advantage to prednisolone, and 7 showed advantage to corticotrophin (see Chart). The difference is significant at the $0.01 \%$ level.

Tables II and III show the overall incidence of denervation in the trial and the breakdown into subgroups. Of the 186 patients treated 141 recovered completely. Of. the 94 who received corticotrophin 32 developed denervation, while of the

*ACTH/CMC-Crookes was used throughout.

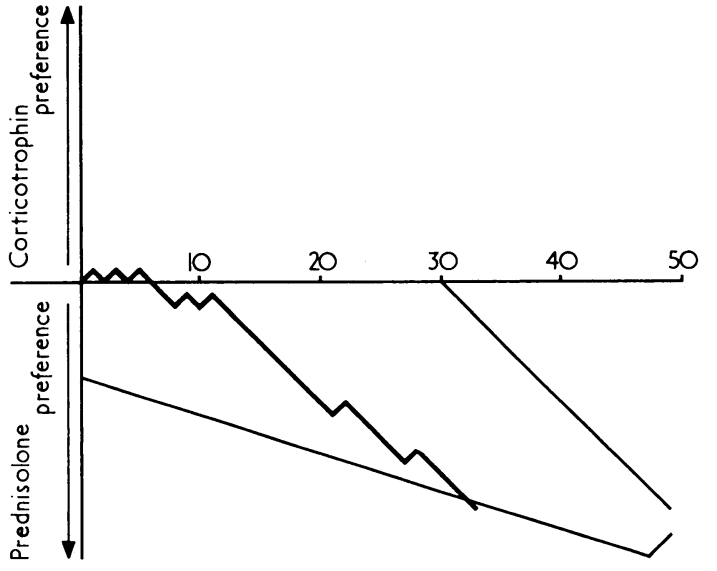

Result of sequential analysis. Corticotrophin preferences upwards. $2 \mathrm{a}=0.01,1-\beta=0.95, \theta=0.80$.

TABLE II-Overall Results of Treatment

\begin{tabular}{ll|c|c|c|c}
\hline Treatment & & $\begin{array}{c}\text { No. } \\
\text { Treated }\end{array}$ & $\begin{array}{c}\text { Complete } \\
\text { Recovery }\end{array}$ & Denervated & $\begin{array}{c}<50 \% \\
\text { Recovery }\end{array}$ \\
\cline { 1 - 2 } $\begin{array}{cc}\text { Corticotrophin } \\
\text { Prednisolone }\end{array}$ & $\cdots$ & 94 & 62 & $32^{*}$ & $6 \dagger$ \\
\hline
\end{tabular}

$* \mathbf{P}<0.005$.

$+\mathrm{P}<0.02$.

TABLE III-Results in the Two Age Groups

\begin{tabular}{|c|c|c|c|c|c|}
\hline Duration & Treatment & $\begin{array}{c}\text { No. } \\
\text { Treated }\end{array}$ & $\begin{array}{l}\text { Complete } \\
\text { Recovery }\end{array}$ & $\begin{array}{c}\text { Dener- } \\
\text { vated }\end{array}$ & $\begin{array}{l}<50 \% \\
\text { Recovery }\end{array}$ \\
\hline \multicolumn{6}{|c|}{ Patients Aged 21 to 45 Years } \\
\hline $\left.\begin{array}{l}1-2 \text { days } \\
3-4 \text { days }\end{array}\right\}$ & $\begin{array}{l}\text { Corticotrophin } \\
\text { Prednisolone } \\
\text { Corticotrophin } \\
\text { Prednisolone }\end{array}$ & $\begin{array}{l}17 \\
17 \\
35 \\
35\end{array}$ & $\begin{array}{l}10 \\
16 \\
24 \\
30\end{array}$ & $\begin{array}{r}7 \\
1 \\
11 \\
5\end{array}$ & $\begin{array}{l}\mathbf{0} \\
\mathbf{0} \\
\mathbf{2} \\
\mathbf{0}\end{array}$ \\
\hline \multicolumn{6}{|c|}{ Patients Aged 46 to 70} \\
\hline $\begin{array}{l}1-2 \text { days } \\
3-4 \text { days }\{\end{array}$ & $\begin{array}{l}\text { Corticotrophin } \\
\text { Prednisolone } \\
\text { Corticotrophin } \\
\text { Prednisolone }\end{array}$ & $\begin{array}{l}16 \\
16 \\
26 \\
24\end{array}$ & $\begin{array}{r}9 \\
12 \\
19 \\
21\end{array}$ & $\begin{array}{l}7 \\
4 \\
7 \\
3\end{array}$ & $\begin{array}{l}3 \\
0 \\
1 \\
0\end{array}$ \\
\hline
\end{tabular}

For statistical significance see text.

92 on prednisolone only 13 failed to recover completely. This difference is statistically highly significant $\left(\chi^{2}=8.99, \mathrm{n}=1\right.$, $0.001<\mathrm{P}<0.005$ ). Of the 104 patients aged 21 to 45 years 80 recovered completely, while 18 on corticotrophin developed denervation against 6 on prednisolone $\left(\chi^{2}=6.55, n=1\right.$, $0.01<P<0.025)$. Of the 82 patients aged 46 to 70 years 61 recovered completely, while 14 on corticotrophin and 7 on prednisolone developed denervation $\left(\chi^{2}=1.93, n=1\right.$, $0.1<\mathrm{P}<0.02$ ).

Analysis of the results in relation to duration of palsy before starting treatment shows that they were better in the earlier cases. Of the 66 patients who were treated in the first two days of paralysis 47 recovered completely, but 14 receiving corticotrophin developed denervation compared with five on prednisolone $\left(\chi^{2}=4.73, n=1,0.025<P<0.05\right)$. Of the 120 who were first treated on the third or fourth day of palsy 94 recovered completely, while 18 on corticotrophin and 8 on prednisolone developed denervation $\left(\chi^{2}=3.60, \mathrm{n}=1,0.05<\mathrm{P}<0.1\right)$.

The mean percentage recovery in all the patients on corticotrophin was assessed at $\mathbf{7 0} \%$ and in the prednisolone patients it was $\mathbf{7 8} \%$. The difference is not statistically significant, but the visual assessment of percentage recovery is crude and unreliable. However, severe denervation with less than $50 \%$ recovery of function is more reliably assessed (Table II). It was found in 6 of the 94 patients on corticotrophin and in none of the 92 on prednisolone $(d=2.38,0.01<P<0.02)$.

Side effects of indigestion and transient oedema were encountered in seven patients, but did not interrupt treatment. 
One patient developed severe haematemesis needing inpatient therapy and had to be withdrawn from the trial. In retrospect it was clear that he should not have been admitted to the trial because he had a history of peptic ulceration.

\section{Discussion}

Controlled trials of treatment in Bell's palsy are difficult to perform because of delay in starting therapy which is likely to prejudice the result. For this reason the patients were subdivided into early and late groups. Sixty-six started treatment on the first or second day of paralysis and 120 on the third or fourth days. The results of earlier treatment were indeed better, though both groups showed benefit. However, in very severe attacks the major damage may be done within the first few hours and treatment should be started at once.

It has previously been shown that the outcome in untreated Bell's palsy becomes worse with increasing age (Langworth and Taverner, 1963) so the patients were further subdivided into young and older groups. There were 104 patients in the young group and 82 in the older group. The expected difference was observed, but in the whole series the mean age of the patients who developed denervation was 44.6 years for the corticotrophin group and 43.9 years for the prednisolone group.

Assessment of the result of treatment is a difficult problem even if very elaborate methods are used. The presence or absence of denervation can be determined by the appearance of associated movements (Langworth and Taverner, 1963), and this is the strictest criterion available. The results now reported are based almost entirely on this finding. We are well aware of the unreliability of subjective estimates of the difference in movement of the two sides of the face, but the statistically significant differences reported here are considerable and it is unlikely that observer error is responsible. The actual assessments of recovery in the severely denervated patients receiving corticotrophin mentioned above were $10 \%, 15 \%, 10 \%, 10 \%$, $15 \%$, and $15 \%$, while all who took prednisolone were assessed at $50 \%$ recovery or above.

We had hoped to show that corticotrophin injections gave better results than oral prednisolone if only because a previous trial of cortisone for Bell's palsy gave a negative result (Taverner, 1954). In retrospect it is clear that the 1954 trial was inadequately planned to produce a reliable result. The treatment was started far too late to be effective, the dose of cortisone was too low, and the number of patients tested was too small.

At present we believe that oral prednisolone is the treatment of choice in Bell's palsy and should be given in full doses from the day of onset. The small risk of serious side effects is acceptable in view of the significant reduction in the incidence of severe denervation.

\section{References}

Jönsson, B., Reis, G. von, and Sahlgren, E. (1951). Acta Psychiatrica et Neurologica, Suppl. No. 74, p. 60 .

Langworth, E. P., and Taverner, D. (1963). Brain, 86, 465.

Miller, H., Newell, D. J., and Ridley, A. (1961). Lancet, 2, 1120

Peiris, O. A., and Miles, D. W. (1965). British Medical fournal, 2, 1162.

Ross, J., Colmant, H. J., and Böhm, P. (1958). Deutsche Zeitschrift für Nervenheilkunde, $177,475$.

Taverner,D. (1954), Lancet, 2, 1052.

Taverner, D., Fearnley, M. E., Kemble, F., Miles, D. W., and Peiris, O. A. (1966). British Medical fournal, 1, 391.

\title{
Thiopropazate Hydrochloride in Persistent Dyskinesia
}

\author{
K. SINGER, M. N. CHENG
}

British Medical fournal, 1971, 4, 22-25

\section{Summary}

Thiopropazate (Dartalan) was found to be significantly more effective than a placebo in relieving dyskinesia in 23 patients with functional psychosis and persistent dyskinesia associated with prolonged phenothiazine therapy. Each patient whose dyskinesia had persisted unchanged for at least one month after phenothiazine withdrawal received thiopropazate by mouth for three weeks and the placebo for a similar period. Patients were evaluated before the trial, at three weeks, and at six weeks.

The drug also improved psychotic behaviour. Possible side effects, which were generally mild, were noted in eight patients, of whom six had Parkinsonism and four drowsiness. None had side effects while on the placebo.

The findings indicate that thiopropazate is of value in persistent dyskinesia associated with prolonged phenothiazine intake-a condition hitherto unresponsive to

\section{University of Hong Kong, Hong Kong}

K. SINGER, M.R.C.P.ED., D.P.M., Lecturer in Psychiatry and Specialist in Charge, Mental Health Service

Castle Peak Hospital, Hong Kong

M. N. CHENG, M.B., B.S., Medical Officer other treatment. Further research is required to determine the long-term effectiveness of the drug.

\section{Introduction}

The treatment of persistent dyskinesia associated with prolonged phenothiazine therapy has been unsatisfactory. Brandrup (1961) reported success with tetrabenazine in four patients (but we could find no further report on the value of this drug) and Roxburgh (1970) used thiopropazate successfully in two patients.

Thiopropazate hydrochloride (Dartalan) is chemically described as 10-(3[4-(2-acetyoxyethyl)piperazin-1-yl]propyl)-2chlorophenothiazine dihydrochloride and is a phenothiazine structurally closely related to chlorpromazine. It has been reported to be of value in schizophrenia (Hamilton et al., 1960). Reports on its effectiveness in controlling choreiform movements have been confined to Huntingdon's chorea (Mathews, 1958; Bruyn, 1962; Lyon, 1962) apart from, so far as we can trace, one case each of non-hereditary chorea (Lyon, 1962), probable senile chorea with polycythaemia (Heathfield, 1968), and Sydenham's chorea activated by oral contraceptives (Lewis and Harrison, 1969). Kabat and McLeod (1959) reported improvement of involuntary movements in 24 cases of cerebellar ataxia and intention tremor.

Persistent dyskinesia affecting the face, mouth, tongue, and jaw (oral dyskinesia) is well known as an insidious and late 